\title{
An Integrated Fuzzy Dephi and Interval-Valued Intuitionistic Fuzzy M-Topsis Model for Design Concept Selection
}

\author{
Daniel O. Aikhuele \\ Faculty of Manufacturing Engineering, Universiti Malaysia Pahang \\ 26600, Pekan, Malaysia \\ danbishop_22@yahoo.co.uk \\ Faiz B. M. Turan \\ Faculty of Manufacturing Engineering, Universiti Malaysia Pahang \\ 26600, Pekan, Malaysia \\ faizmzt@ump.edu.my
}

\begin{abstract}
In this paper, the Modified Technique for Order Preference by Similarity to the Ideal Solution (M-TOPSIS) model has been extended into the intuitionistic fuzzy environment. By applying the improved score function first, to represent the aggregated effect of positive and negative evaluations in the performance ratings of the alternatives based on interval-valued intuitionistic fuzzy set (IVIFS) data and in combination with the weighted normalized Euclidean distance for the computation of the separation measures of alternative(s) for the intuitionistic positive and negative ideal solutions. The two methods which have been used for the computation of the separation measure have been integrated using a new reflection defuzzification integration formula which has been introduced in this study. To prove the efficacy of the proposed model, the model have been applied for the evaluation and selection design concept for a new printed circuit board (PCB), and for a modified hypothetical example which is based on the selection of a preferred Naval vessel as a reference for a new design.
\end{abstract}

Keywords: M-TOPSIS; Improved score function; Weighted normalized Euclidean distance; Intuitionistic fuzzy set; Design concept selection

\section{Introduction}

In solving multi-criteria decision-making (MCDM) problems, such as in equipment selection, material selection and in the evaluation of process performance etc., it is required that several factors/criteria are considered simultaneously before selecting or ranking alternatives. The Decision-Makers (DMs), preferred alternative(s) are chosen by providing the preference information in the form of exact numerical values, interval values (Joshi \& Kumar, 2014) or in the form of linguistic variables (Nguyen, Dawal, Nukman, Aoyama, \& Case, 2015). However, according to Hosseininasab \& Dehghanbaghi,(Hosseininasab \& Dehghanbaghi, 2015) such preferences information's are often characterized by ambiguity due to vagueness and uncertainty. This ambiguity due to vagueness and uncertainty has remained one of the big challenges for DMs during the last several years and this has resulted in more and more interest in the topic from researchers.

In handling vagueness and uncertainty issues, Zadeh (Zadeh, 1965), who introduced the concept of fuzzy set theory, has outlined how the fuzzy set concept could be used for characterizing complex systems and decision-making problems. This breakthrough resulted in the extension of the different MCDM techniques in fuzzy environment. One of 
such extension includes; the fuzzy technique for order preference by similarity to ideal solution (fuzzy-TOPSIS) which was developed by Hwang and Yoon in 1981 (Hwang C. L. \& Yoon K., 1981). The fuzzy-TO PSIS model which is one of the most widely used MCDM methods and has found application in several fields with much-reported works on its applications. Some of the fields of studies identified include; Accounting (Bulgurcu, 2012), Management (Jadidi, Hong, \& Firouzi, 2008), Agriculture (Pakpour, Olishevska, Prasher, Milani, \& Chénier, 2013), Chemical science (Soufi, Ghobadian, Najafi, Sabzimaleki, \& Yusaf, 2015), Design (Yang \& Wu, 2008), Business (Ghazanfari, Rouhani, \& Jafari, 2014), Engineering (Zhu, Wang, Liang, Li, \& Sun, 2012), Health and medicine (Chou, Yu, Dewabharata, \& Dat, 2012), etc.

However, due to some of its limitation, many different improvement and modifications have been proposed and applied in recent years, prominently among this improvement include the M-TOPSIS model by Ren et al., in 2007 (Ren, Zhang, Wang, \& Sun, 2007). M-TOPSIS which is an abbreviation of Modified Technique for Order Preference by Similarity to the Ideal Solution was presented to meet the need for a better and simpler approach with special regard to the TOPSIS rankings. It creates an understanding of the inherent relationship between the Relative closeness $(R)$ value and alternative evaluation. The M-TOPSIS method is "described as the process of calculating the distance between the alternatives and the reference points in the $\mathrm{D}+\mathrm{D}-$-plane by constructing the $R$ value to evaluate the quality of the alternative" (Ren et al., 2007) (see figure 1).

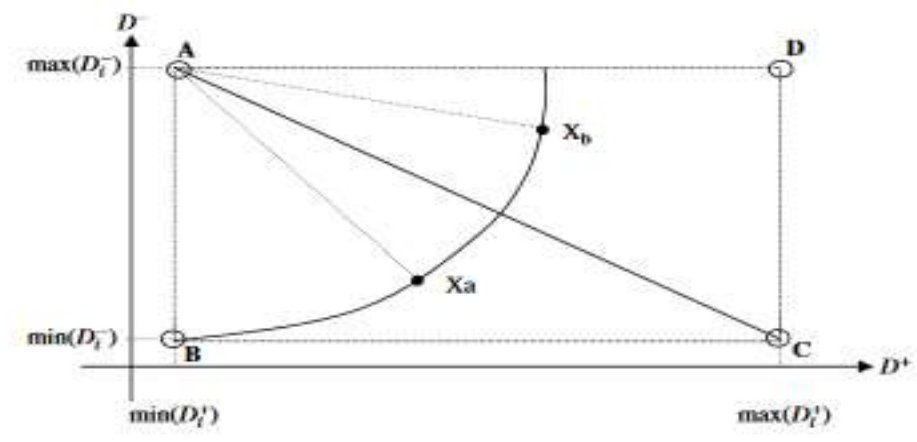

Fig 1. The idea of 'M-TOPSIS' method (Ren et al., 2007).

The M-TOPSIS method is unique for its ability to solve ranking reversal issue which is one of the drawbacks of the TOPSIS model and to evaluate failure when alternatives are symmetrical.

In 1986, Atanassov extended the fuzzy set theory to form a new theory called intuitionistic fuzzy set (IFS) theory (Atanassov, 1986). Unlike the traditional fuzzy set theory, the IFS theory is characterized by a membership function and a non-membership function. According to Datta et al., (Saurav Datta, Chitrasen Samantra, Siba Sankar Mahapatra, Goutam Mondal, Partha Sarathi Chakraborty, 2013) the IFS theory are more capable than the traditional fuzzy sets at handling vagueness and uncertainty information in practice. While Liu \& Wang, (H.-W. Liu \& Wang, 2007), Xu \& Liao, (Xu \& Liao, 2015) and $\mathrm{Xu} \&$ Liao, (Xu, Member, \& Liao, 2013) has described three (3) benefits of applying IFS theory in practice to include; (1) IFSs are able to model unknown information using hesitation degree, that is in a situation where the DMs are not sure 
about the preferences of an alternative(s), the IFS theory method is most suitable to represent the opinions of the experts as compared to the fuzzy sets. (2) It represents three grades of membership function which include membership degree, non-membership degree, and hesitancy degree, and (3) all fuzzy numbers in the IFS theory can all be used to represent vagueness of "agreement" but, cannot depict the "disagreement" of the DMs however. Hence, the IFS can be said to consider opinions from three sides to arrive at preferred one.

Extensive literature review show that the application of IFS in MCDM problems has increased significantly over the past few years, with many research literature published both on the theoretical and practical aspects of its applications (Bai, 2013; Chen \& Chiou, 2015; Jahromi, 2012; Li, 2005; Lin, Yuan, \& Xia, 2007; M. Liu \& Ren, 2014; Xu, 2014), where this is due to the fact that IFS are more capable than the traditional fuzzy sets at handling vagueness and uncertainty information in practice as stated above.

In summary, this paper extends the Modified Technique for Order Preference by Similarity to the Ideal Solution (M-TOPSIS) model for an intuitionistic fuzzy environment by implementing partly the intuitionistic algorithm proposed by Bai,(Bai, 2013), which uses improved score function for the separation measures of alternative(s) for the positive and negative ideal solutions. In improving the result and to avoid the bias of using a single separation distance measure or the confusion in determining the specific separation distance measure that is fittest which is almost becoming a decision-making problem itself, due to the many methods approaches available. This study will be exploring the application of an additional distance method (the weighted normalized Euclidean distance). The result from the improved score function method application is made robust by integrating it with the weighted normalized Euclidean distance method using a new reflection defuzzification integration formula.

The relative importance of the criteria used in this study has been determined using the fuzzy Delphi (FD) method, by expressing the collected values in Triangular Fuzzy Number; however other values are collected and expressed in Interval-valued intuitionistic fuzzy numbers.

The proposed integrated fuzzy Delphi method and Interval-valued Intuitionistic fuzzy MTOPSIS (IVIF-MTOPSIS) model has been applied to a real life case study by evaluating and selecting the best design concept for a new printed circuit board (PCB) and for a modified hypothetical example which is based on the selection of a preferred Naval vessel as a reference for a new design.

The rest of the paper is organized as follows; Section 2 briefly presents the concept of IVIFS and the FD method. The IVIF-MTOPSIS model is presented in section 3. In section 4, a real case study and a modified hypothetical example originally presented by Ye,(Ye, 2009) is applied to demonstrate the proposed method and to compared the result of the model. Finally in section 5, the conclusion is presented.

\section{Preliminaries}

In this section, the fundamental definitions and concepts of IVIFS as described by Bai (Bai, 2013) is presented. 


\subsection{Interval-valued Intuitionistic Fuzzy Set}

\section{Definition 1}

Let $\mathrm{D}[0,1]$ be the set of all closed subintervals of the interval $[0,1]$ and let $\mathrm{X}(\neq \varnothing)$ be a given set. An IVIFS $A$ in $X$ is expressed as (Bai, 2013) (Ye, 2009);

$$
A=\left\{\left\langle x, \mu_{A}(x), v_{A}(x)\right\rangle \mid x \in X\right\},
$$

where $\mu_{A}: X \rightarrow \mathrm{D}[0,1], v_{A}: X \rightarrow \mathrm{D}[0,1]$ with the condition $0 \leq \sup \mu_{A}(x)+$ $\sup v_{A}(x) \leq 1, \forall x \in X$.

The intervals $\mu_{A}(x)$ and $v_{A}(x)$ denote, respectively, the degree of membership and nonmembership of the element $x$ to the set $A$. Thus, for each $x \in X$ the intervals $\mu_{A}(x)$ and $v_{A}(x)$ are closed and their lower and upper end points are denoted by $\mu_{A L}(x), \mu_{A U}(x), v_{A L}(x)$ and $v_{A u}(x)$ respectively. We can denote the set as;

$$
A=\left\{\left\langle x,\left[\mu_{A L}(x), \mu_{A U}(x)\right],\left[v_{A L}(x), v_{A U}(x)\right]\right\rangle \mid x \in X\right\},
$$

where $0 \leq \mu_{A U}(x)+v_{A U}(x) \leq 1, \mu_{A L}(x) \geq 0, v_{A L}(x) \geq 0$

For each element $x$, we can compute the unknown degree (hesitancy degree) of an intuitionistic fuzzy interval of $x \in X$ in $A$ which is defined as follows:

$$
\pi_{A}(x)=1-\mu_{A}(x)-v_{A}(x)=\left[1-\mu_{A L}(x)-\mu_{A U}(x), 1-\mu_{A L}(x)-v_{A L}(x)\right]
$$

However, if $\mu_{A}(x)=\mu_{A L}(x)=\mu_{A U}(x)$ and $v_{A}(x)=v_{A L}(x)=v_{A U}(x)$, then the given IVIFS $A$ is reduced to an ordinary IFS. For convenience, the IVIFS can also be expressed as $A=([a, b],[c, d])$.

In order to make comparisons between two IVIFSs, metric methods have been introduced by several researchers $(\mathrm{Li}, 2010)(Y e, 2009)$, however, in this study we will be concern with the improved score function originally proposed by Bai (Bai, 2013), for the ranking, and the representation of the aggregated effect of positive and negative evaluations in the performance ratings of the alternatives based on IVIFS data in the M-TOPSIS model. The computation formula for the improved score function is given as;

$$
I(A)=\frac{a+a(1-a-c)+b+b(1-b-d)}{2}, \text { where } I(A) \in[0,1]
$$

When $a=b$ and $c=d$, the IVIFS will degenerate to the IFS while the improved score function of IVIFS will degenerate to the score function of IFS proposed by Ye, (Ye, 2009).

\subsection{Fuzzy Delphi (FD) Method}

The Fuzzy Delphi (FD) method which is an extension of the traditional Delphi method was proposed by Ishikawa et al.,(Ishikawa et al., 1993) to improve and handle vagueness and uncertainties in its application. The FD method which integrates expert's opinions with fuzzy numbers by using the concepts of cumulative frequency distribution and fuzzy integral to handle the ambiguities due to the differences in the meanings and 
understanding of the experts' opinions and estimates (Wu, 2010), can be called a collective decision-making method (Linstone \& Turoff, 2002).

Due to the easy computation of the FD methodology, it has found applications in several fields including management (Tahriri, Mousavi, Hozhabri Haghighi, \& Zawiah Md Dawal, 2014), engineering (Hsu, Lee, \& Kreng, 2010), construction (Vrinda \& Kalappa, 2014) etc. In an attempt to handle the many uncertainties in the expert's opinions several approaches has been adopted including the use of triangular fuzzy number, Gaussian fuzzy number, trapezoidal fuzzy number and triangular membership function (Hsu et al., 2010). However, in this study, the Triangular Fuzzy Number is applied. The FD method is used to determine the weight of the criteria in this study and its algorithm is given below.

\section{Algorithm of the FD Method and the IVIF-MTOPSIS Model}

In this section, the algorithm for the proposed integrated model is concisely expressed using the stepwise procedure. The implementation steps which is partly from (Bai, 2013) algorithm has been modified to suit the present study. The schematic diagram of the proposed integrated model is shown in Fig 1 below.

Step 1. Set up a group of Decision Makers (DMs). With their opinion construct the interval-valued intuitionistic fuzzy decision matrix $(\widetilde{\mathrm{D}})$ of the alternatives $\left(A_{i}\right)$ with respect to the criteria $\left(C_{i}\right)$, using linguistic variables and the interval-valued intuitionistic fuzzy number (IVIFN) (see Table 1)

$$
\begin{aligned}
& \boldsymbol{x}_{i j}=\left(\left[a_{i j}, b_{i j}\right],\left[c_{i j}, d_{i j}\right]\right), \quad i=1,2, \ldots, m ; j=1, \ldots, n \\
& \boldsymbol{D}_{m x n}\left(\boldsymbol{x}_{i j}\right)=\left[\begin{array}{cccc}
\left(\left[\boldsymbol{a}_{11}, b_{11}\right],\left[c_{11}, d_{11}\right]\right) & \cdots & \cdots & \left(\left[a_{1 n}, b_{1 n}\right],\left[c_{1 n}, d_{1 n}\right]\right) \\
\left(\left[a_{21}, b_{21}\right],\left[c_{21}, d_{21}\right]\right) & \cdots & \cdots & \left(\left[a_{2 n}, b_{2 n}\right],\left[c_{2 n}, d_{2 n}\right]\right) \\
\vdots & \vdots & \ddots & \vdots \\
\vdots & \vdots & \ddots & \vdots \\
\left(\left[a_{m 1}, b_{m 1}\right],\left[c_{m 1}, d_{m 1}\right]\right) & \cdots & \cdots & \left(\left[a_{m n}, b_{m n}\right],\left[c_{m n}, d_{m n}\right]\right)
\end{array}\right]
\end{aligned}
$$

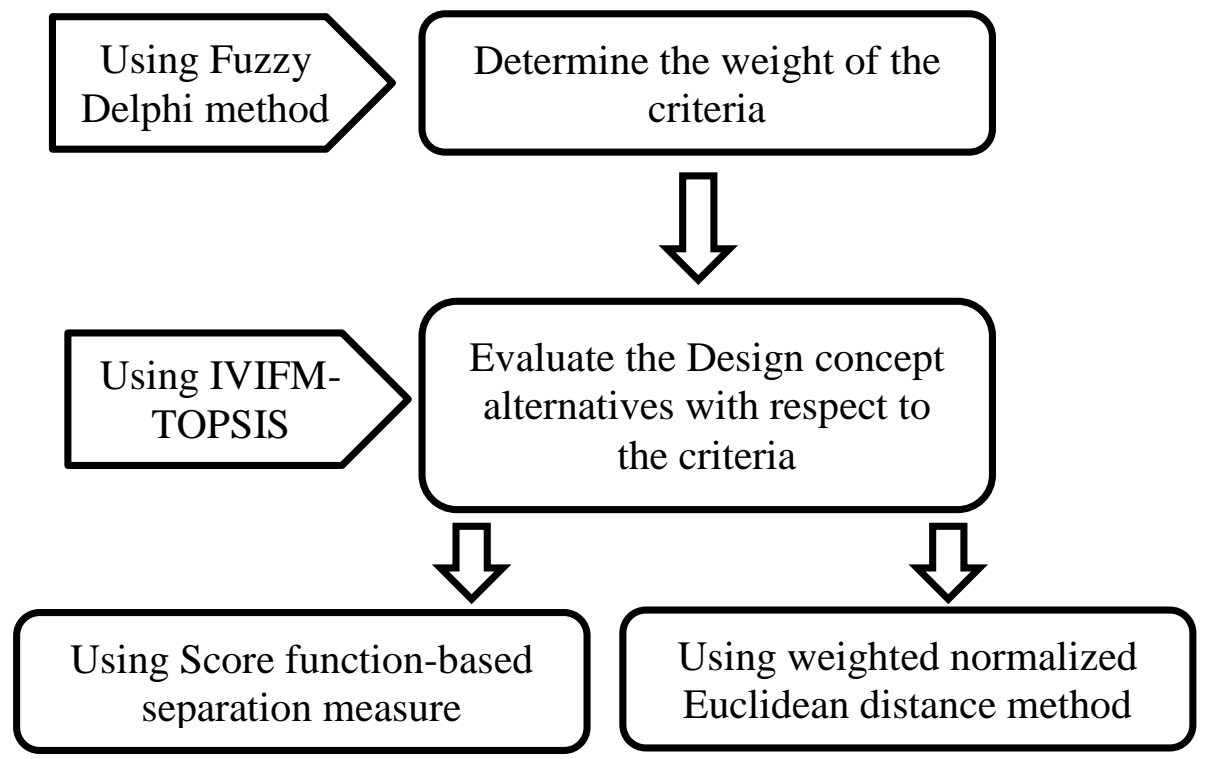




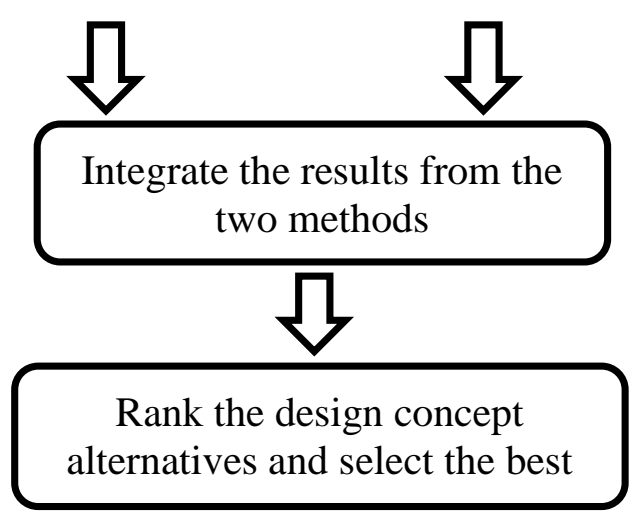

Fig 1. The schematic diagram of the proposed integrated model

Step 2. Convert the interval-valued fuzzy decision matrix $\boldsymbol{D}_{\boldsymbol{m} \boldsymbol{x} \boldsymbol{n}}\left(\boldsymbol{x}_{\boldsymbol{i j}}\right)$ to the improved score matrix $\boldsymbol{R}_{\boldsymbol{m} \boldsymbol{x n}}\left(\boldsymbol{I}_{\boldsymbol{i} \boldsymbol{j}}\left(\boldsymbol{a}_{\boldsymbol{i} j}\right)\right)$. The main purpose of this step is to represent the aggregated effect of positive and negative evaluations in the performance ratings of the alternatives based on interval-valued intuitionistic fuzzy set (IVIFS) data as given by the DMs.

$$
R_{m x n}\left(I_{i j}\left(a_{i j}\right)\right)=\left[\begin{array}{cccc}
I_{11}\left(x_{11}\right) & I_{12}\left(x_{12}\right) & \ldots & I_{1 n}\left(x_{1 n}\right) \\
I_{22}\left(x_{22}\right) & I_{22}\left(x_{22}\right) & \ldots & I_{2 n}\left(x_{2 n}\right) \\
\vdots & \vdots & \ddots & \vdots \\
\vdots & \vdots & \ddots & \vdots \\
I_{m 1}\left(x_{m 1}\right) & I_{m 2}\left(x_{m 2}\right) & \cdots & I_{m n}\left(x_{m n}\right)
\end{array}\right]
$$

Step 3. Determine the weight of each of the evaluating criteria $w_{j}$ using the FD method. This is achieved by first collecting opinions of the decision group concerning the criteria, using linguistic variables and then converts to the TFN.

- Calculate the evaluation value of the TFN of each alternate criteria given by DMs, and find out the significance TFN of the alternate criteria.

Example 1. Let's assume the evaluation value of the significance of $n$ element given by $m$ DMs is $\boldsymbol{x}_{\boldsymbol{i} \boldsymbol{j}}=\left(a_{\boldsymbol{i} \boldsymbol{j}}, b_{i j}, \boldsymbol{c}_{\boldsymbol{i j}}\right), i=1,2, \ldots, n ; j=1, \ldots, m$ then the fuzzy weight of the $n$ element is; $w_{j}=\left(a_{j}, b_{j}, c_{j}\right), \quad j=1, \ldots, m$

$$
w_{j}=\left(\frac{\sum_{i j}^{m} a_{i j}}{m}, \frac{\sum_{i j}^{m} b_{i j}}{m}, \frac{\sum_{i j}^{m} c_{i j}}{m}\right)
$$

Finally, the result is defuzzified using center of gravity method;

$$
\boldsymbol{w}_{j}=\frac{a_{j}+b_{j}+c_{j}}{3}
$$

Step 4. Define the Positive Ideal Solution $\left(A^{+}\right)$and Negative Ideal Solution $\left(A^{-}\right)$for the score function-based matrix;

$$
\begin{aligned}
& A^{+}=\left(\left[a_{j}, \boldsymbol{b}_{j}\right],\left[c_{j}, d_{j}\right]\right), A^{-}=\left(\left[a_{j}, \boldsymbol{b}_{j}\right],\left[c_{j}, d_{j}\right]\right), \\
& A^{+}=([1,1],[0,0]), \quad j=1, \ldots, n
\end{aligned}
$$




$$
A^{-}=([0,0],[1,1]), \quad j=1, \ldots, n
$$

Table 1: Intuitionistic Fuzzy Numbers for approximating the linguistic variable

\begin{tabular}{c|cc}
\hline Linguistic terms & $\begin{array}{c}\text { Interval-valued intuitionistic } \\
\text { fuzzy Number }\end{array}$ & $\begin{array}{c}\text { Triangular Fuzzy Numbers } \\
(\text { TFN) }\end{array}$ \\
\hline Very low (VL) & $([0.1,0.3],[0.25,0.4])$ & $(0.1,0.25,0.3)$ \\
Low (L) & $([0.2,0.55],[0.3,0.55])$ & $(0.2,0.3,0.55)$ \\
Good (G) & $([0.3,0.6],[0.45,0.65])$ & $(0.3,0.45,0.6)$ \\
High (H) & $([0.5,0.7],[0.6,0.7])$ & $(0.5,0.6,0.7)$ \\
Excellent (EX) & $([0.6,0.9],[0.75,1.0])$ & $(0.6,0.75,0.9)$ \\
\hline
\end{tabular}

Step 5. Compute the score function-based separation measures $\left(d^{+}{ }_{i}\left(A^{+}, \boldsymbol{A}_{\boldsymbol{i}}\right)\right.$ and $\left(d^{-}{ }_{i}\left(A^{-}, \boldsymbol{A}_{\boldsymbol{i}}\right)\right.$ for each alternative from the positive ideal and negative ideal solutions using the equation (11) and (12), also for the weighted normalized Euclidean distance method, the separation measures is calculated for $\left(d^{+}{ }_{i}\left(A^{+}, A_{i}\right)\right.$ and $\left(d^{-}{ }_{i}\left(A^{-}, A_{i}\right)\right.$ in intuitionistic fuzzy environment as shown respectively in the equations (13) and (14) (Wang \& Li, 2012) below.

$$
d^{+}{ }_{i}\left(A^{+}, A_{i}\right)=\sqrt{\sum_{i=1}^{n}\left[w_{j}\left(1-\left(\boldsymbol{I}_{\boldsymbol{i j}}\left(\boldsymbol{x}_{\boldsymbol{i j}}\right)\right)\right]^{2}\right.}
$$

Similarly,

$$
\begin{aligned}
& d^{-}{ }_{i}\left(A^{-}, \boldsymbol{A}_{\boldsymbol{i}}\right)=\sqrt{\sum_{i=1}^{n}\left[w_{j}\left(\boldsymbol{I}_{\boldsymbol{i} j}\left(\boldsymbol{x}_{\boldsymbol{i j}}\right)\right)\right]^{2}} \\
& d^{+}{ }_{i}\left(A^{+}, \boldsymbol{A}_{\boldsymbol{i}}\right)=\left(\frac { 1 } { 4 } \sum _ { j = 0 } ^ { n } w _ { j } \left(\left(a_{i j}-a_{j}\right)^{2}+\left(b_{i j}-b_{j}\right)^{2}+\left(c_{i j}-c_{j}\right)^{2}+\right.\right. \\
&\left.\left(d_{i j}-d_{j}\right)^{2}+\left(\pi^{l}{ }_{i j}-\pi^{l}{ }_{j}\right)^{2}+\left(\pi^{u}{ }_{i j}-\pi^{u}{ }_{j}\right)^{2}\right)^{1 / 2}
\end{aligned}
$$

Similarly,

$$
\begin{gathered}
d^{-}{ }_{i}\left(A^{-}, \boldsymbol{A}_{i}\right)=\left(\frac { 1 } { 4 } \sum _ { j = 0 } ^ { n } w _ { j } \left(\left(a_{i j}-a_{j}\right)^{2}+\left(b_{i j}-b_{j}\right)^{2}+\left(c_{i j}-c_{j}\right)^{2}+\right.\right. \\
\left.\left(d_{i j}-d_{j}\right)^{2}+\left(\pi_{i j}^{l}-\pi_{j}^{l}\right)^{2}+\left(\pi_{i j}^{u}-\pi_{j}^{u}\right)^{2}\right)^{1 / 2}
\end{gathered}
$$

Where $\pi_{i j}^{l}=1-b_{i j}-d_{i j}, \pi_{i j}^{u}=1-a_{i j}-c_{i j}, \pi_{j}^{l}=1-b_{j}-d_{j}$ and $\pi_{j}^{u}=1-$ $a_{j}-c_{j}$

Step 6. To combine the distance separation measure proposed in this study, the new reflection defuzzification integration formula is applied as shown in equation (15) and (16) for both the positive and negative distance points respectively.

$$
D^{+}{ }_{i}\left(A^{+}, A_{i}\right)_{\text {total }}=\alpha_{1} d^{+}{ }_{i}\left(A^{+}, A_{i}\right)+\alpha_{2} d^{+}{ }_{i}\left(A^{+}, A_{i}\right)
$$

Similarly,

$$
D^{-}{ }_{i}\left(A^{-}, A_{i}\right)_{\text {total }}=\alpha_{1} d^{-}{ }_{i}\left(A^{-}, A_{i}\right)+\alpha_{2} d^{-}{ }_{i}\left(A^{-}, A_{i}\right)
$$


where $\alpha_{1}+\alpha_{2}=1$

Step 7. Set a point, say $B$ as the optimized ideal references point $\left(d_{i}\left(A, \boldsymbol{A}_{\boldsymbol{i}}\right)\right.$, for the alternatives that is; $B\left(\min d\left(A^{+}, \boldsymbol{A}_{\boldsymbol{i}}\right), \max d\left(A^{-}, \boldsymbol{A}_{\boldsymbol{i}}\right)\right)$. Then calculate the distances from each alternative. The relative closeness $R_{i}$ to the ideal solution is calculated as shown in the equation,

$R_{i}=\sqrt{\left[\left(d\left(A^{+}, A_{i}\right),-\min d\left(A^{+}, A_{i}\right)\right)^{2}+\left(d\left(A^{-}, A_{i}\right),-\max d\left(A^{-}, A_{i}\right)^{2}\right]\right.}$

Step 8. Rank the preference order.

\section{Application of the Proposed Model}

In this section, we demonstrate the computational process of the Fuzzy Delphi and Interval-Valued Intuitionistic Fuzzy M-TOPSIS algorithm proposed herein, by using a real case study for case 1 and a hypothetical example for case 2, this is mainly to compare the effectiveness of the model.

Case 1. An electronic related manufacturing company located around Pekan area Malaysia needed to select a preferred printed circuit board (PCB) from a group of candidates; $A_{1}, A_{2}, A_{3}$ and $A_{4}$ as a reference PCB for a new design. A group of three experts from the product development unit, manufacturing, and management within the company i.e. E1, E2, and E3 was tasked to determine the most appropriate PCB design from the candidates with respect to following twelve (12) criteria; Mass and size $\left(C_{1}\right)$, Ergonomics $\left(\mathrm{C}_{2}\right)$, Simple assembly $\left(\mathrm{C}_{3}\right)$, Easy handling $\left(\mathrm{C}_{4}\right)$, Easy maintenance $\left(\mathrm{C}_{5}\right)$, Few production errors $\left(\mathrm{C}_{6}\right)$, Cost $\left(\mathrm{C}_{7}\right)$, Fewer spec controls $\left(\mathrm{C}_{8}\right)$, Safety standard $\left(\mathrm{C}_{9}\right)$, Fulfills environmental standard $\left(\mathrm{C}_{10}\right)$, Attractive design $\left(\mathrm{C}_{11}\right)$, and Modifiable $\left(\mathrm{C}_{12}\right)$.

Using the assessment report from the three experts, we implement the proposed FD method and the Interval-Valued Intuitionistic Fuzzy M-TOPSIS model. Summary of the implementation is given below.

Step 1: Construct the interval-valued intuitionistic fuzzy decision matrix; the study uses the linguistic variables in Table 1 and then the interval-valued intuitionistic fuzzy number to express the ratings of the four concepts $A_{i}$ with respect to each of the twelve criteria $C_{j}$ to form the interval-valued intuitionistic fuzzy decision matrix $\boldsymbol{D}_{\boldsymbol{m} \boldsymbol{x} \boldsymbol{n}}\left(\boldsymbol{x}_{\boldsymbol{i} \boldsymbol{j}}\right)$ as shown in Table $2 \& 3$.

Table 2: Expert's ratings with Linguistic terms

\begin{tabular}{c|cccccccccccc}
\hline$C_{i}$ & $E 1$ & $E 2$ & $E 3$ & $E 1$ & $E 2$ & $E 3$ & $E 1$ & $E 2$ & $E 3$ & $E 1$ & $E 2$ & E3 \\
\hline & & $\mathrm{A}_{1}$ & & & $\mathrm{~A}_{2}$ & & & $\mathrm{~A}_{3}$ & & & $\mathrm{~A}_{4}$ & \\
$\mathrm{C} 1$ & $\mathrm{~L}$ & $\mathrm{G}$ & $\mathrm{VL}$ & $\mathrm{H}$ & $\mathrm{L}$ & $\mathrm{H}$ & $\mathrm{VL}$ & $\mathrm{H}$ & $\mathrm{G}$ & $\mathrm{G}$ & $\mathrm{L}$ & $\mathrm{VL}$ \\
$\mathrm{C}_{2}$ & $\mathrm{H}$ & $\mathrm{H}$ & $\mathrm{VL}$ & $\mathrm{EX}$ & $\mathrm{G}$ & $\mathrm{EX}$ & $\mathrm{L}$ & $\mathrm{EX}$ & $\mathrm{H}$ & $\mathrm{VL}$ & $\mathrm{G}$ & $\mathrm{L}$ \\
$\mathrm{C}_{3}$ & $\mathrm{EX}$ & $\mathrm{EX}$ & $\mathrm{L}$ & $\mathrm{VL}$ & $\mathrm{H}$ & $\mathrm{H}$ & $\mathrm{G}$ & $\mathrm{H}$ & $\mathrm{EX}$ & $\mathrm{L}$ & $\mathrm{H}$ & $\mathrm{G}$ \\
$\mathrm{C}_{4}$ & $\mathrm{H}$ & $\mathrm{H}$ & $\mathrm{G}$ & $\mathrm{L}$ & $\mathrm{G}$ & $\mathrm{G}$ & $\mathrm{L}$ & $\mathrm{L}$ & $\mathrm{VL}$ & $\mathrm{G}$ & $\mathrm{L}$ & $\mathrm{VL}$ \\
\hline
\end{tabular}




\begin{tabular}{c|cccccccccccc}
\hline $\mathrm{C}_{5}$ & H & G & L & G & H & G & H & G & L & L & G & L \\
$\mathrm{C}_{6}$ & VL & G & H & H & EX & H & EX & L & VL & G & H & G \\
$\mathrm{C}_{7}$ & L & H & VL & EX & H & H & L & G & L & H & G & H \\
$\mathrm{C}_{8}$ & H & EX & L & VL & EX & EX & G & H & G & G & H & L \\
$\mathrm{C}_{9}$ & VL & H & H & VL & H & H & VL & G & VL & G & VL & G \\
$\mathrm{C}_{10}$ & L & VL & EX & L & EX & EX & L & L & L & H & L & H \\
$\mathrm{C}_{11}$ & G & L & H & VL & H & H & G & G & G & EX & G & H \\
$C_{12}$ & VL & H & G & H & H & G & VL & H & H & L & EX & G \\
\hline
\end{tabular}

Table 3: Interval-valued intuitionistic fuzzy decision matrix

\begin{tabular}{|c|c|c|c|c|}
\hline & $A_{l}$ & $A_{2}$ & $A_{3}$ & $A_{4}$ \\
\hline $\mathrm{C}_{1}$ & $\begin{array}{l}([0.20,0.48], \\
[0.33,0.53])\end{array}$ & $\begin{array}{l}([0.40,0.65], \\
[0.50,0.65])\end{array}$ & $\begin{array}{c}([0.30,0.53] \\
[0.43,0.58])\end{array}$ & $\begin{array}{l}([0.20,0.48] \\
[0.33,0.53])\end{array}$ \\
\hline $\mathrm{C}_{2}$ & $\begin{array}{c}([0.37,0.57], \\
[0.48,0.6])\end{array}$ & $\begin{array}{l}([0.47,0.80], \\
[0.65,0.88])\end{array}$ & $\begin{array}{l}([0.43,0.72] \\
[0.55,0.70])\end{array}$ & $\begin{array}{l}([0.20,0.48] \\
[0.33,0.53])\end{array}$ \\
\hline $\mathrm{C}_{3}$ & $\begin{array}{c}([0.43,0.67], \\
[0.55,0.85])\end{array}$ & $\begin{array}{c}([0.27,0.58], \\
[0.4,0.60])\end{array}$ & $\begin{array}{c}([0.17,0.47] . \\
[0.28,0.75])\end{array}$ & $\begin{array}{l}([0.20,0.48] \\
[0.33,0.63])\end{array}$ \\
\hline $\mathrm{C}_{4}$ & $\begin{array}{c}([0.33,0.62], \\
[0.45,0.68])\end{array}$ & $\begin{array}{l}([0.37,0.63], \\
[0.50,0.62])\end{array}$ & $\begin{array}{c}([0.33,0.62] \\
[0.45,0.78])\end{array}$ & $\begin{array}{l}([0.23,0.57] \\
[0.35,0.53])\end{array}$ \\
\hline $\mathrm{C}_{5}$ & $\begin{array}{c}([0.30,0.53], \\
[0.43,0.63])\end{array}$ & $\begin{array}{l}([0.53,0.77], \\
[0.65,0.68])\end{array}$ & $\begin{array}{c}([0.30,0.58] \\
[0.43,0.50])\end{array}$ & $\begin{array}{l}([0.37,0.63] \\
[0.50,0.58])\end{array}$ \\
\hline $\mathrm{C}_{6}$ & $\begin{array}{l}([0.27,0.52], \\
[0.38,0.58])\end{array}$ & $\begin{array}{l}([0.53,0.77], \\
[0.65,0.90])\end{array}$ & $\begin{array}{l}([0.23,0.57] \\
[0.63,0.35])\end{array}$ & $\begin{array}{l}([0.43,0.67] \\
[0.55,0.67])\end{array}$ \\
\hline $\mathrm{C}_{7}$ & $\begin{array}{c}([0.43,0.72], \\
[0.55,0.55])\end{array}$ & $\begin{array}{l}([0.43,0.70], \\
[0.58,0.65])\end{array}$ & $\begin{array}{c}([0.37,0.63] \\
[0.58,0.50])\end{array}$ & $\begin{array}{l}([0.33,0.62] \\
[0.45,0.67])\end{array}$ \\
\hline $\mathrm{C}_{8}$ & $\begin{array}{c}([0.37,0.57], \\
{[0.48,0.78)}\end{array}$ & $\begin{array}{l}([0.37,0.57], \\
[0.48,0.88])\end{array}$ & $\begin{array}{l}([0.17,0.40], \\
[0.32,0.67])\end{array}$ & $\begin{array}{l}([0.23,0.50] \\
[0.38,0.63])\end{array}$ \\
\hline $\mathrm{C}_{9}$ & $\begin{array}{c}([0.30,0.58], \\
[0.43,0.6])\end{array}$ & $\begin{array}{l}([0.47,0.78], \\
[0.60,0.60])\end{array}$ & $\begin{array}{l}([0.20,0.55], \\
[0.30,0.48])\end{array}$ & $\begin{array}{c}([0.40,0.65] \\
[0.50,0.57])\end{array}$ \\
\hline $\mathrm{C}_{10}$ & $\begin{array}{c}([0.33,0.62], \\
[0.45,0.65])\end{array}$ & $\begin{array}{l}([0.37,0.57], \\
[0.48,0.85])\end{array}$ & $\begin{array}{l}([0.30,0.60] \\
[0.45,0.55])\end{array}$ & $\begin{array}{l}([0.47,0.73] \\
[0.60,0.65])\end{array}$ \\
\hline $\mathrm{C}_{11}$ & $\begin{array}{l}(0.30,0.58] \\
[0.43,0.63])\end{array}$ & $\begin{array}{l}([0.10,0.30], \\
[0.25,0.60])\end{array}$ & $\begin{array}{l}([0.23,0.43] \\
[0.37,0.65])\end{array}$ & $\begin{array}{l}([0.43,0.67] \\
[0.55,0.78])\end{array}$ \\
\hline $\mathrm{C}_{12}$ & $\begin{array}{l}(0.40,0.65] \\
[0.50,0.58])\end{array}$ & $\begin{array}{l}([0.27,0.58], \\
[0.40,0.68])\end{array}$ & $\begin{array}{l}([0.33,0.62], \\
[0.45,0.60])\end{array}$ & $\begin{array}{c}([0.37,0.68] \\
[0.50,0.73])\end{array}$ \\
\hline
\end{tabular}

Step 2: Using the improved score function (equation (3)) the interval-valued intuitionistic fuzzy decision matrix $\boldsymbol{D}_{\boldsymbol{m} \boldsymbol{x n}}\left(\boldsymbol{x}_{\boldsymbol{i j}}\right)$ is converted to the improved score matrix $\boldsymbol{R}_{\boldsymbol{m} \boldsymbol{x} \boldsymbol{n}}\left(\boldsymbol{I}_{\boldsymbol{i} \boldsymbol{j}}\left(\boldsymbol{a}_{\boldsymbol{i j}}\right)\right)$ (i.e. equation (10)) as show in the Table 4. Also, by following the implementation procedure for the Fuzzy Delphi method, the weights of the criteria are determined. The results for criteria weights are shown in Table 5. 
Table 4: Improved score matrix

\begin{tabular}{c|cccccccccccc}
\hline & $C_{1}$ & $C_{2}$ & $C_{3}$ & $C_{4}$ & $C_{5}$ & $C_{6}$ & $C_{7}$ & $C_{8}$ & $C_{9}$ & $C_{10}$ & $C_{11}$ & $C_{12}$ \\
\hline $\mathrm{A}_{1}$ & 0.385 & 0.449 & 0.380 & 0.418 & 0.413 & 0.416 & 0.482 & 0.398 & 0.428 & 0.428 & 0.420 & 0.470 \\
$\mathrm{~A}_{2}$ & 0.448 & 0.335 & 0.417 & 0.445 & 0.429 & 0.344 & 0.440 & 0.370 & 0.460 & 0.378 & 0.248 & 0.394 \\
$\mathrm{~A}_{3}$ & 0.426 & 0.428 & 0.315 & 0.387 & 0.457 & 0.439 & 0.468 & 0.314 & 0.417 & 0.443 & 0.359 & 0.443 \\
$\mathrm{~A}_{4}$ & 0.385 & 0.385 & 0.361 & 0.420 & 0.455 & 0.440 & 0.421 & 0.377 & 0.474 & 0.445 & 0.404 & 0.410 \\
\hline
\end{tabular}

Table 5: Fuzzy Delphi weight

\begin{tabular}{c|cccccccccccc}
\hline$C_{i}$ & $C_{1}$ & $C_{2}$ & $C_{3}$ & $C_{4}$ & $C_{5}$ & $C_{6}$ & $C_{7}$ & $C_{8}$ & $C_{9}$ & $C_{10}$ & $C_{11}$ & $C_{12}$ \\
\hline $\boldsymbol{w}_{\boldsymbol{j}}$ & 0.086 & 0.086 & 0.084 & 0.083 & 0.086 & 0.079 & 0.081 & 0.084 & 0.079 & 0.081 & 0.084 & 0.088 \\
\hline
\end{tabular}

Step 3: By using equation (11) and (12), we can compute $\left(d^{+}{ }_{i}\left(A^{+}, A_{i}\right)\right.$ and $\left(d^{-}{ }_{i}\left(A^{-}\right.\right.$, $\left.A_{i}\right)(i=1,2,3,4)$ for the score function-based approach and the final result is as follows;

$$
\begin{gathered}
\left(d^{+}{ }_{1}\left(A^{+}, A_{1}\right)=0.167,\left(d^{-}{ }_{1}\left(A^{-}, A_{1}\right)=0.123\right.\right. \\
\left(d^{+}{ }_{2}\left(A^{+}, A_{2}\right)=0.177,\left(d^{-}{ }_{2}\left(A^{-}, A_{2}\right)=0.115,\right.\right. \\
\left(d^{+}{ }_{3}\left(A^{+}, A_{3}\right)=0.172,\left(d^{-}{ }_{3}\left(A^{-}, A_{3}\right)=0.119,\right. \text { and }\right. \\
\left(d^{+}{ }_{4}\left(A^{+}, A_{4}\right)=0.170,\left(d^{-}{ }_{4}\left(A^{-}, A_{4}\right)=0.120,\right.\right.
\end{gathered}
$$

Similarly, using equation (13) and (14) the weighted Euclidean distance method for the separation measure is calculated and the results are as follows;

$$
\begin{gathered}
\left(d^{+}{ }_{1}\left(A^{+}, A_{1}\right)=0.586,\left(d^{-}{ }_{1}\left(A^{-}, A_{1}\right)=0.510\right.\right. \\
\left(d^{+}{ }_{2}\left(A^{+}, A_{2}\right)=0.629,\left(d^{-}{ }_{2}\left(A^{-}, A_{2}\right)=0.541,\right.\right. \\
\left(d^{+}{ }_{3}\left(A^{+}, A_{3}\right)=0.601,\left(d^{-}{ }_{3}\left(A^{-}, A_{3}\right)=0.516\right.\right. \\
\left(d^{+}{ }_{4}\left(A^{+}, A_{4}\right)=0.594,\left(d^{-}{ }_{4}\left(A^{-}, A_{4}\right)=0.523 .\right.\right.
\end{gathered}
$$

Step 4: Upon using the new reflection defuzzification integration formula in equation (15) and (16), the two separation measures approaches are integrated and the results are as follows;

$$
\begin{gathered}
\left(D^{+}\left(A^{+}, \boldsymbol{A}_{\mathbf{1}}\right)=0.753,\left(D^{-}{ }_{1}\left(A^{-}, \boldsymbol{A}_{1}\right)=0.633,\right.\right. \\
\left(D^{+}{ }_{2}\left(A^{+}, \boldsymbol{A}_{2}\right)=0.806,\left(D^{-}{ }_{2}\left(A^{-}, \boldsymbol{A}_{2}\right)=0.656,\right.\right. \\
\left(D^{+}{ }_{3}\left(A^{+}, \boldsymbol{A}_{3}\right)=0.773,\left(D^{-}{ }_{3}\left(A^{-}, A_{3}\right)=0.635,\right. \text { and }\right. \\
\left(D^{+}{ }_{4}\left(A^{+}, A_{4}\right)=0.764,\left(D^{-}{ }_{4}\left(A^{-}, A_{4}\right)=0.643 .\right.\right.
\end{gathered}
$$

Step 5: Finally, the results for the relative closeness $R_{i},(i=1,2,3,4)$ to the ideal solution which is calculated using equation (17) is given as $R_{1}=0.023, R_{2}=0.053, R_{3}=$ 0.029 , and $R_{4}=0.017$, therefore the ranking orders for the four candidates are in the form (increasing order) $A_{4}<A_{1}<A_{3}<A_{2}$ ), obviously, $A_{4}$ is the best candidate according to the model. 
Case 2. A hypothetical example originally presented by Ye, (2009) is modified to demonstrate the computational process of the Interval-Valued Intuitionistic Fuzzy MTOPSIS algorithm.

Let us consider a decision-making problem for the selecting a preferred Naval vessel from a group of candidates; $S_{1}, S_{2}, S_{3}$ and $S_{4}$ as a reference for a new design. The expert has to make a decision according to the following, Performance $\left(\mathrm{C}_{1}\right)$, Economy $\left(\mathrm{C}_{2}\right)$ and Appearance $\left(\mathrm{C}_{3}\right)$ (Xie et al., 2008). The weights of the criteria are $W=$ $\{0.35,0.25,0.40\}$.

The preferred car is to be evaluated using the interval-valued intuitionistic fuzzy MTOPSIS algorithm with respect to the above criteria. Following the implementation step for the interval-valued intuitionistic fuzzy M-TOPSIS model, the interval-valued intuitionistic fuzzy decision matrix decision matrix $\boldsymbol{D}_{\boldsymbol{m} \boldsymbol{x} \boldsymbol{n}}\left(\boldsymbol{x}_{\boldsymbol{i} \boldsymbol{j}}\right)$ is determined, then the improved score matrix $\boldsymbol{R}_{\boldsymbol{m} \boldsymbol{x} \boldsymbol{n}}\left(\boldsymbol{I}_{\boldsymbol{i} \boldsymbol{j}}\left(\boldsymbol{a}_{\boldsymbol{i j}}\right)\right)$.

$$
\begin{aligned}
& \boldsymbol{D}_{4 x 3}\left(\boldsymbol{x}_{\boldsymbol{i} \boldsymbol{j}}\right)=\left[\begin{array}{lll}
([0.4,0.5],[0.3,0.4]) & ([0.4,0.6],[0.2,0.4]) & ([0.1,0.3],[0.5,0.6]) \\
([0.6,0.7],[0.2,0.3]) & ([0.6,0.7],[0.2,0.3]) & ([0.4,0.7],[0.1,0.2]) \\
([0.3,0.6],[0.3,0.4]) & ([0.5,0.6],[0.3,0.4]) & ([0.5,0.6],[0.1,0.3]) \\
([0.7,0.8],[0.1,0.2]) & ([0.6,0.7],[0.1,0.3]) & ([0.3,0.4],[0.1,0.2])
\end{array}\right] \\
& \boldsymbol{R}_{\boldsymbol{m x n}}\left(\boldsymbol{I}_{\boldsymbol{i j}}\left(\boldsymbol{a}_{\boldsymbol{i j}}\right)\right)=\left[\begin{array}{lll}
0.5350 & 0.5800 & 0.2350 \\
0.7100 & 0.7100 & 0.6850 \\
0.5100 & 0.6000 & 0.6800 \\
0.8200 & 0.7400 & 0.5200
\end{array}\right]
\end{aligned}
$$

Same as in Case 1 , we can compute $\left(d^{+}{ }_{i}\left(A^{+}, A_{i}\right)\right.$ and $\left(d^{-}{ }_{i}\left(A^{-}, A_{i}\right)(i=1,2,3,4)\right.$ for the score function-based approach and the results are as follows;

$$
\begin{gathered}
\left(d^{+}{ }_{1}\left(A^{+}, A_{1}\right)=0.362,\left(d^{-}{ }_{1}\left(A^{-}, A_{1}\right)=0.255\right.\right. \\
\left(d^{+}{ }_{2}\left(A^{+}, A_{2}\right)=0.177,\left(d^{-}{ }_{2}\left(A^{-}, A_{2}\right)=0.410,\right.\right. \\
\left(d^{+}{ }_{3}\left(A^{+}, A_{3}\right)=0.236,\left(d^{-}{ }_{3}\left(A^{-}, A_{3}\right)=0.358\right. \text { and }\right. \\
\left(d^{+}{ }_{4}\left(A^{+}, A_{4}\right)=0.212, \quad\left(d^{-}{ }_{4}\left(A^{-}, A_{4}\right)=0.400 .\right.\right.
\end{gathered}
$$

Similarly, for the weighted Euclidean distance method the results are;

$$
\begin{gathered}
\left(d^{+}{ }_{1}\left(A^{+}, A_{1}\right)=0.589,\left(d^{-}{ }_{1}\left(A^{-}, A_{1}\right)=0.540,\right.\right. \\
\left(d^{+}{ }_{2}\left(A^{+}, A_{2}\right)=0.373,\left(d^{-}{ }_{2}\left(A^{-}, A_{2}\right)=0.734,\right.\right. \\
\left(d^{+}{ }_{3}\left(A^{+}, A_{3}\right)=0.452,\left(d^{-}{ }_{3}\left(A^{-}, A_{3}\right)=0.655\right. \text { and }\right. \\
\left(d^{+}{ }_{4}\left(A^{+}, A_{4}\right)=0.434\left(d^{-}{ }_{4}\left(A^{-}, A_{4}\right)=0.769 .\right.\right.
\end{gathered}
$$

Also, upon integration of the two approaches with the new reflection defuzzification integration formula in equation the results are as follows;

$$
\begin{aligned}
\left(D^{+}\left(A^{+}, A_{1}\right)\right. & =0.951,\left(D^{-}{ }_{1}\left(A^{-}, A_{1}\right)=0.795\right. \\
\left(D^{+}{ }_{2}\left(A^{+}, A_{2}\right)\right. & =0.550,\left(D^{-}{ }_{2}\left(A^{-}, A_{2}\right)=1.144\right.
\end{aligned}
$$




$$
\begin{gathered}
\left(D^{+}{ }_{3}\left(A^{+}, A_{3}\right)=0.688,\left(D^{-}{ }_{3}\left(A^{-}, A_{3}\right)=1.014,\right. \text { and }\right. \\
\left(D^{+}{ }_{4}\left(A^{+}, A_{4}\right)=0.647,\left(D^{-}{ }_{4}\left(A^{-}, A_{4}\right)=1.169 .\right.\right.
\end{gathered}
$$

Finally, the results for the relative closeness $R_{i},(i=1,2,3,4)$ to the ideal solution is given as $R_{1}=0.548, R_{2}=0.024, R_{3}=0.208$, and $R_{4}=0.097$, therefore the ranking orders for the four candidates are in the form $A_{2}<A_{4}<A_{3}<A_{1}$, where alternative $A_{2}$ is adjudged to be the best candidate and is in agreement with the result in (Ye, 2009) as shown in Table 6. Also the result has been compared with the traditional TOPSIS model.

\section{Table 6: Comparison of result}

\begin{tabular}{c|cccccc}
\hline & $\begin{array}{c}\text { Relative } \\
\text { closeness of } \\
\text { the Proposed } \\
\text { model }\end{array}$ & Rank & $\begin{array}{c}\text { Ye (Ye, } \\
\text { 2009) }\end{array}$ & Rank & TOPSIS & Rank \\
\hline$A_{1}$ & 0.548 & 4 & 0.1459 & 4 & 0.455 & 4 \\
$A_{2}$ & 0.024 & 1 & 0.4330 & 1 & 0.675 & 1 \\
$A_{3}$ & 0.208 & 3 & 0.3124 & 3 & 0.596 & 3 \\
$A_{4}$ & 0.097 & 2 & 0.3647 & 2 & 0.644 & 2 \\
\hline
\end{tabular}

\section{Conclusions}

This paper presents a reliable, easy and a more objective approach for ranking and determining preference in a multi-criteria decision-making problem, by extending the Modified Technique for Order Preference by Similarity to the Ideal Solution (MTOPSIS) model into the intuitionistic fuzzy environment. The study has applied the improved score function matrix, first to represent the aggregated effect of positive and negative evaluations in the performance ratings of the alternatives based on intervalvalued intuitionistic fuzzy set (IVIFS) data and in combination with the weighted normalized Euclidean distance method for the computation of the separation measures of alternative(s) for the intuitionistic positive and negative ideal solutions. While the criteria weight have been determined using the fuzzy Delphi (FD) method.

The proposed integrated fuzzy Delphi method and Interval-valued Intuitionistic fuzzy MTOPSIS (IVIF-MTOPSIS) model has been applied to a real life case study, for the evaluation and selection design concept for a new printed circuit board (PCB), and for a hypothetical example which is based on the selection of a preferred Naval vessel as a reference for a new design.

The result from this study, is hope to serve as an advisory system and a guide for decision makers, business organizations, industry managers etc. planning to select new design concepts, select business partners, and equipment suppliers as well as in the evaluation of current practices and status. Finally, in the future, we hope to apply the proposed model to other domains. 


\section{Reference}

1. Atanassov, K. T. (1986). Intuitionistic fuzzy sets. Fuzzy Sets and Systems, 20(1), 87-96. https://doi.org/10.1016/S0165-0114(86)80034-3

2. Bai, Z. (2013). An Interval-Valued Intuitionistic Fuzzy TOPSIS Method Based on an Improved Score Function. The Scientific World Journal, 2013, 1-9.

3. Bulgurcu, B. (2012). Application of TOPSIS Technique for Financial Performance Evaluation of Technology Firms in Istanbul Stock Exchange Market. Procedia - Social and Behavioral Sciences, 62, 1033-1040. https://doi.org/10.1016/j.sbspro.2012.09.176

4. Chen, S. M., \& Chiou, C. H. (2015). A new method for multiattribute decision making based on interval-valued intuitionistic fuzzy sets, PSO techniques and evidential reasoning methodology. Proceedings - International Conference on Machine Learning and Cybernetics, 1(6), 403-409. https://doi.org/10.1109/ICMLC.2014.7009149

5. Chou, S. Y., Yu, V. F., Dewabharata, A., \& Dat, L. Q. (2012). A fuzzy TOPSIS approach for medical provider selection and evaluation. 2012 International Conference on Fuzzy Theory and Its Applications, iFUZZY 2012, 322-326.

6. Ghazanfari, M., Rouhani, S., \& Jafari, M. (2014). A fuzzy TOPSIS model to evaluate the Business Intelligence competencies of Port Community Systems. Polish Maritime Research, 21(2), 86-96. https://doi.org/10.2478/pomr-2014-0023

7. Hosseininasab, H., \& Dehghanbaghi, M. (2015). A Fuzzy Expert System for Supporting Returned Products Strategies. International Journal of Industrial Engineering: Theory, Applications and Practice, 22(2).

8. Hsu, Y., Lee, C., \& Kreng, V. B. (2010). The application of Fuzzy Delphi Method and Fuzzy AHP in lubricant regenerative technology selection. Expert Systems With Applications, 37(1), 419-425. https://doi.org/10.1016/j.eswa.2009.05.068

9. Hwang C. L., \& Yoon K. (1981). Multiple Attribute Decision Making Methods and Applications. Berlin: Springer.

10. Ishikawa, A., Amagasa, M., Shiga, T., Tomizawa, G., Tatsuta, R., \& Mieno, H. (1993). The max-min Delphi method and fuzzy Delphi method via fuzzy integration. Fuzzy Sets and Systems, 55(3), 241-253.

11. Jadidi, O., Hong, T., \& Firouzi, F. (2008). TOPSIS and fuzzy multi-objective model integration for supplier selection problem. Journal of Achievements in Materials and Manufactuing Engineering, 31(2), 762-769.

12. Jahromi, M. K. (2012). Multiattribute decision making models and methods using intuitionistic fuzzy sets. International Mathematical Forum, 7(57), 2847-2851. https://doi.org/10.1016/j.jcss.2004.06.002

13. Joshi, D., \& Kumar, S. (2014). Intuitionistic fuzzy entropy and distance measure based TOPSIS method for multi-criteria decision making. Egyptian Informatics Journal, 15(2), 97104. https://doi.org/10.1016/j.eij.2014.03.002

14. Li, D.-F. (2005). Multiattribute decision making models and methods using intuitionistic fuzzy sets. Journal of Computer and System Sciences, 70(1), 73-85. https://doi.org/10.1016/j.jcss.2004.06.002

15. Li, D.-F. (2010). Multiattribute decision making method based on generalized OWA operators with intuitionistic fuzzy sets. Expert Systems with Applications, 37(12), 8673-8678. https://doi.org/10.1016/j.eswa.2010.06.062

16. Lin, L., Yuan, X. H., \& Xia, Z. Q. (2007). Multicriteria fuzzy decision-making methods based on intuitionistic fuzzy sets. Journal of Computer and System Sciences,73(1),84-88.

17. Linstone, H. a, \& Turoff, M. (2002). The Delphi Method - Techniques and applications. Book, 1-616. https://doi.org/10.2307/1268751

18. Liu, H.-W., \& Wang, G.-J. (2007). Multicriteria fuzzy decision-making methods based on intuitionistic fuzzy sets. European Journal of Operational Research, 179, 220-233.

19. Liu, M., \& Ren, H. (2014). A New Intuitionistic Fuzzy Entropy and Application in Multi- 
Attribute Decision Making. Information, 5(4), 587-601. https://doi.org/10.3390/info5040587

20. Nguyen, H., Dawal, S. Z., Nukman, Y., Aoyama, H., \& Case, K. (2015). An Integrated Approach of Fuzzy Linguistic Preference Based AHP and Fuzzy COPRAS for Machine Tool Evaluation. PLoS ONE, 10(9), 1-25. https://doi.org/10.1371/journal.pone.0133599

21. Pakpour, S., Olishevska, S. V, Prasher, S. O., Milani, A. S., \& Chénier, M. R. (2013). DNA extraction method selection for agricultural soil using TOPSIS multiple criteria decisionmaking model. American Journal of Molecular Biology, 215-228.

22. Ren, L., Zhang, Y., Wang, Y., \& Sun, Z. (2007). Comparative analysis of a novel M-TOPSIS method and topsis. Applied Mathematics Research eXpress, 2007, 1-10. https://doi.org/10.1093/amrx/abm005

23. Saurav Datta, Chitrasen Samantra, Siba Sankar Mahapatra, Goutam Mondal, Partha Sarathi Chakraborty, G. M. (2013). Selection of internet assessment vendor using TOPSIS method in fuzzy environment. International Journal of Business Performance and Supply Chain Modelling, 5(1), 1-27. https://doi.org/10.1504/IJBPSCM.2013.051645

24. Soufi, M. D., Ghobadian, B., Najafi, G., Sabzimaleki, M. R., \& Yusaf, T. (2015). TOPSIS multi-criteria decision modeling approach for biolubricant selection for two-stroke petrol engines. Energies, 8(12), 13960-13970. https://doi.org/10.3390/en81212408

25. Tahriri, F., Mousavi, M., Hozhabri Haghighi, S., \& Zawiah Md Dawal, S. (2014). The application of fuzzy Delphi and fuzzy inference system in supplier ranking and selection. Journal of Industrial Engineering International, 10(3), 66. https://doi.org/10.1007/s40092014-0066-6

26. Vrinda, T., \& Kalappa, M. S. (2014). Application of Fuzzy Delphi Method for the selection of factors influencing the selection of best bridge site. International Journal of Innovation and Applied Sciences, 9(4), 1687-1690.

27. Wang, Z. J., \& Li, K. W. (2012). An interval-valued intuitionistic fuzzy multiattribute group decision making framework with incomplete preference over alternatives. Expert Systems with Applications, 39(18), 13509-13516. https://doi.org/10.1016/j.eswa.2012.07.007

28. Wu, K. (2010). Applying the Fuzzy Delphi Method to Analyze the Evaluation Indexes for Service Quality after Railway Re-Opening - Using the Old Mountain Line Railway as an Example. Recent Researches in System Science, 474-479.

29. Xie, X., Xu, D. L., Yang, J. B., Wang, J., Ren, J., \& Yu, S. (2008). Ship selection using a multiple-criteria synthesis approach. Journal of Marine Science and Technology, 13(1), 5062. https://doi.org/10.1007/s00773-007-0259-4

30. $\mathrm{Xu}, \mathrm{Z}$. (2014). Intuitionistic preference modeling and interactive decision making. In Studies in Fuzziness and Soft Computing (pp. 195-223). https://doi.org/10.1007/978-3-642-28403-8

31. Xu, Z., \& Liao, H. (2015). A survey of approaches to decision making with intuitionistic fuzzy preference relations. Knowledge-Based Systems, 80, 131-142. https://doi.org/10.1016/j.knosys.2014.12.034

32. Xu, Z., Member, S., \& Liao, H. (2013). Intuitionistic fuzzy analytic hierarchy process. IEEE Transactions on Fuzzy Systems, 22(4), 1. https://doi.org/10.1109/TFUZZ.2013.2272585

33. Yang, C., \& Wu, Q. (2008). Decision Model for Product Design Based on Fuzzy TOPSIS Method. 2008 International Symposium on Computational Intelligence and Design, 342-345. https://doi.org/10.1109/ISCID.2008.220

34. Ye, J. (2009). Multicriteria fuzzy decision-making method based on a novel accuracy function under interval-valued intuitionistic fuzzy environment. Expert Systems with Applications, 36(3), 6899-6902. https://doi.org/DOI 10.1016/j.eswa.2008.08.042

35. Zadeh, L. A. (1965). Fuzzy sets. Information and Control, 8, 338-353. https://doi.org/10.1016/S0019-9958(65)90241-X

36. Zhu, X., Wang, F., Liang, C., Li, J., \& Sun, X. (2012). Quality credit evaluation based on TOPSIS: Evidence from air-conditioning market in China. Procedia Computer Science, 9(10), 1256-1262. https://doi.org/10.1016/j.procs.2012.04.137 